\title{
Oral versus topical carbonic anhydrase inhibitors in ocular hypertension after scleral tunnel cataract surgery
}

This article was published in the following Dove Press journal:

Clinical Ophthalmology

10 June 2009

Number of times this article has been viewed

\author{
Abdulmoghni Al-Barrag' \\ Motaher Al-Shaer' \\ Nabil Al-Matary ${ }^{2}$ \\ Mahfoud Bamashmous' \\ 'Ophthalmic Department, Faculty \\ of Medicine and Health Sciences, \\ Sana'a University, Sana'a, Republic \\ of Yemen; ${ }^{2}$ Ophthalmic Department, \\ Military Hospital, Sana'a, Republic \\ of Yemen
}

Purpose: To compare the effect of oral acetazolamide and topical $2 \%$ dorzolamide in prevention of ocular hypertension after scleral tunnel cataract surgery.

Setting: Ophthalmic department, Sana'a University, Yemen Sana'a from March 2007 to October 2007.

Methods: This prospective double-blind, randomized study included 150 eyes undergoing scleral tunnel cataract surgery with hard posterior chamber intraocular implantation. Methylcellulose was used as the viscoelastic in all surgery cases. Patients were assigned to one of three groups: group 1: topical gentamicin eye drops (control; $n=52$ ); group 2: systemic acetazolamide $250 \mathrm{mg}(\mathrm{n}=45)$; and group 3 : topical $2 \%$ dorzolamide $(\mathrm{n}=53)$. Acetazolamide patients received one $250 \mathrm{mg}$ tablet, one hour before surgery, then half a tablet every eight hours. A topical dorzolamide $2 \%$ or gentamicin was applied in one drop one hour before surgery then every eight hours, for three days postoperatively. Intraocular pressures (IOP) were measured by Goldman applanation tonometry one hour preoperatively and 16, 24, and 48 hours postoperatively.

Results: At 16 hours, IOP between the three groups increased significantly with a statistically significant p-value of 0.008 , but the mean IOP of acetazolamide patients was less than other groups. IOP nearly returned to the normal level 24 and 48 hours postoperatively, but this was not statistically significant ( $\mathrm{p}=0.452$ and 0.138 , respectively).

Conclusion: Acetazolamide offers better IOP control than topical dorzolamide $2 \%$ in preventing ocular hypertension after scleral tunnel cataract surgery.

Keywords: cataract surgery, ocular hypertension, viscoelastic, dorzolamide, intraocular pressure

\section{Introduction}

A major reason for subsequent day assessment is to detect raised intraocular pressure (IOP), which complicates almost $8 \%$ of all cataract extractions. ${ }^{1}$ Postoperative IOP increase is the most frequent short-term complication of cataract surgery. ${ }^{2-4}$ It has become a major concern as an increasing number of cataract patients are having surgery in an outpatient setting and are discharged soon after surgery. Increasing demand for cataract surgery is resulting in a greater emphasis on high volume day-case procedures, where postoperative care varies widely from center to center, with little evidence-based practice. It is common for patients to be routinely assessed on the day after surgery, necessitating a further hospital visit. ${ }^{5,6}$

Postoperative assessment on the day of surgery will detect not only a spike of IOP, but also most early surgically related complications such as wound leak, iris prolapse, and a dislocated intraocular lens (IOL). Viscoelastic substances are widely used in small incision cataract surgery with several advantages. It has the maintenance of the anterior 
chamber space, protection of the corneal endothelium, and facilitation of the surgical procedure, especially during anterior capsulotomy and IOL implantation. It has some disadvantage of causing an increase in IOP within the first 24 hours after cataract surgery. ${ }^{7-16}$ However, in small-incision cataract surgery there are occasional spikes of $30 \mathrm{mmHg}$ or higher with the use of sodium hyaluronate. ${ }^{17}$ Chakraborty and colleagues recommended the routine use of oral acetazolamide after phacoemulsification. ${ }^{18}$ Systemic carbonic anhydrase inhibitors (CAIs) are associated with adverse effects such as acid-base disturbance, hypersensitivity reactions, and fatal aplastic anemia. ${ }^{11,19-21}$

We report a prospective double-blind randomized study where acetazolamide was given in select patients as a prophylactic IOP-lowering treatment after manual sutureless scleral tunnel cataract surgery with posterior chamber intraocular lens (PC IOL) implantation.

\section{Patients and methods}

This prospective double-blind randomized study comprised 150 eyes from 150 consecutive patients (68 males and 82 females) with unilateral uncomplicated age-related cataract. All patients were scheduled for manual sutureless scleral tunnel cataract surgery with poly(methyl methacrylate) (PMMA) hard posterior chamber IOL implantation. Exclusion criteria included patients with history of glaucoma or lens-induced glaucoma and ocular hypertension more than $25 \mathrm{mmHg}$. Patients presenting with IOP less than $10 \mathrm{mmHg}$ were excluded. Patients with uveitis, sublaxating or dislocating crystalline lens, or previous ocular surgery or laser treatment were not involved in this study. Intraoperative posterior capsule rupture or vitreous loss was eliminated from the study. All patients with age-related cataract including hypermature and pseudoexfoliation syndrome with cataract were included in this study.

The preoperative baseline IOP was measured before using dilating drops, then Goldmann applanation tonometry one hour before surgery. Patients were randomly assigned to one of three groups based on the type of IOP-lowering medication given at one hour before surgery: group 1: one drop of gentamicin (control eyes); group 2: one tablet of acetazolamide (Cidamex) $250 \mathrm{mg}$; group 3: one drop of dorzolamide 2\% (Xola) instead of apraclonidine due to its unavailability in the Yemen market. The ophthalmic nurse in our study was the only one to know which group received one of the three types of medications one hour before surgery immediately after taking the base IOP. All patients were operated on in the same fashion by the same consultant ophthalmologist. Dilating drops (phenylephrine $2.5 \%$, tropicamide $0.5 \%$ ) were instilled in the operated eye approximately one to two hours before surgery. At the time of this study, phacoemulsification was not started yet and extracapsular cataract surgery with PC IOL was the standard technique for cataract surgery in our department.

Peribulbar anesthesia of lidocaine hydrochloride $2 \%$ was used in all cases. The operated eye was sterilized with povidone-iodine 5\% solution for two minutes. After peribulbar anesthesia was administered, a fornixbased conjunctival flap was done, followed by adequate electrocautery for homeostasis, and then a 6 to $7 \mathrm{~mm}$ scleral tunnel incision curving away from the limbus "frown " incision from 11 o'clock to 1 o'clock position was performed by the same surgeon. Another temporal 2-mm corneal tunnel paracentesis incision was applied. The viscoelastic (methylcellulose) substance was injected into the anterior chamber. This was followed by capsulorrhexis, hydrodissection, and prolapse of the nucleus into the anterior chamber. Delivery of the nucleus using irrigating victus was followed by irrigation aspiration of the cortical materials remnants and cleaning of the capsular bag using Ringer's lactate solution. The anterior chamber and capsular bag was expanded with the viscoelastic substance and a hard PMMA IOL implanted in the capsular bag. The viscoelastic substance was aspirated from the anterior chamber using an irrigation/aspiration (I/A) cannula. The incision was left sutureless while the conjunctiva was closed by electrocautery. No miotic agent was used intracamerally for all surgical patients. Capsule rupture did not occur in all cases. After surgery, the eye was patched after subconjunctival injection of gentamicin-dexamethasone.

After this, ophthalmic assistance was the administration of antiglaucoma drugs according to the subdivision of the patients, control group (gentamicin) eyedrops every eight hours, the second group received acetazolamide $250 \mathrm{mg}$ half tablet every eight hours, while the third group received topical dorzolamide $2 \%$ (Xola) eyedrops every eight hours.

After $16+2$ hours visits, dexamethasone $1 \%$ eye drops were used five times a day, then followed by measuring the IOP at 16, 24, and 48 hours after surgery. The IOP in the operated eye was measured by an ophthalmic resident unaware of the patient's group assignment using a Goldmann applanation tonometer.

The SPSS program (version 13; SPSS Inc., Chicago, IL, USA) was used to analyze the data of this study. Group comparisons of mean with standard deviation were associated with P-value in preoperative and postoperative IOP using a one-way ANOVA test. The mean IOP involving the standard deviation changes from preoperatively to 16 hours, and 24 to 
48 hours postoperatively were calculated by paired sample $t$-test. The preoperative $\mathrm{P}$ value was compared to those after 16,24 , and 48 hours in each group by ANOVA tests.

\section{Results}

This study includes 150 eyes from 150 patients who had surgery between March 2007 and October 2007. All patients were Yemeni in origin. All surgeries were completed by one consultant ophthalmologist without intraoperative complications.

The mean age was almost equal in all groups with a male-tofemale ratio of 26:26 in the control group, 18:27 in the acetazolamide group, and 24:29 in the dorzolamide group (Table 1).

Table 2 shows the mean preoperative and postoperative IOP which peaked at 16 hours in all three groups and returned to nearly preoperative values by 48 hours. The mean IOP preoperatively was significantly lower in the dorzolamide group when compared between and within groups $(p=0.035)$. Sixteen hours postoperatively, the mean IOP was significantly lower in the acetazolamide group than in the control and dorzolamide groups, respectively, while within groups highly statistically significant $(\mathrm{p}=0.008)$. At 24 and 48 hours IOP within groups ( $p=0.452$ and 0.138 , respectively) returned to nearly basal IOP.

The mean difference in IOP changes from preoperatively to 16 hours, and 24 to 48 hours, postoperatively is shown in Table 3. The mean difference in IOP was almost equal in all groups without significant difference. At 24 and 48 hours, the mean IOP went down in all groups with no significant difference between groups.

Six (11.4\%) control patients had an IOP of $>30 \mathrm{mmHg}$ or higher at 16 hours compared with seven (12.3\%) dorzolamide patients and only one (2.2\%) acetazolamide patient. All of those patients with a previous diagnosis did not have glaucoma or ocular hypertension in the operated eye.

\section{Discussion}

We found in this study that acetazolamide controls the rising IOP in the first 48 hours of manual sutureless scleral tunnel

Table I Patient characteristics

\begin{tabular}{llll}
\hline Character & $\begin{array}{l}\text { Control } \\
\text { group }\end{array}$ & $\begin{array}{l}\text { Acetazolamide } \\
\text { group }\end{array}$ & $\begin{array}{l}\text { Dorzolamide } \\
\text { group }\end{array}$ \\
\hline No of eyes & 52 & 45 & 53 \\
Mean age (years) & $63.05 \pm 9.53$ & $60.15 \pm 12.08$ & 63.88 \\
Age range (years) & 46 & 59 & 55 \\
Sex (M:F) & $26: 26$ & $18: 27$ & $24: 29$ \\
\hline
\end{tabular}

Notes: All mean \pm standard deviations for mean age. cataract surgery with hard posterior chamber PMMA IOL implantation. IOP usually starts to rise two to four hours after surgery and lasts up to 24 hours, when most of the viscoelastic material has left the anterior chamber through the outflow channels. ${ }^{19-21}$ Some studies assessing the frequency of a clinically significant elevation in IOP after cataract surgery found IOP to be transiently raised in $2.3 \%$ to $8.9 \%$ of cases. ${ }^{19,22}$ Some causes contributing to elevated IOP after cataract surgery such as use of viscoelastic material ${ }^{23}$ and retained lens matter may also cause uveitis and shooting of IOP after surgery. Prostaglandin releases after cataract surgery also play a role in elevated IOP.${ }^{19-22,24,25}$ Postoperative hyphema may occasionally cause an increased IOP by red blood cell blockage of the trabecular meshwork. Postoperative increase in IOP may be associated with pain, corneal edema, optic nerve damage, and visual field loss in patients with pre-existing glaucoma. Various drugs, including the systemic CAIs, timolol, pilocarpine gel, intracameral acetylcholine, and carbachol have been studied as agents to prevent postoperative IOP spikes. ${ }^{24-31}$

One of the primary functions of the next-day review visit is to measure and treat significantly raised IOP. Discharging patients a few hours after surgery may miss several patient guidelines. Many patients at risk of significant morbidity from a persistently raised postoperative IOP may not be detected otherwise. A lot of studies done in this field so far have been to detect and treat early shooting of IOP postoperatively.

In this study, we found that the IOP peaked after 16 hours postoperatively in the control $(p=0.000)$ and dorzolamide groups $(\mathrm{p}=0.000)$, and acetazolamide patients had a statistically insignificant increase $(\mathrm{p}=0.288)$, while IOP increased statistically significantly between groups $(p=0.008)$. This agrees with earlier studies in patients after extracapsular surgery in which IOP peaked six to eight hours postoperatively. ${ }^{32-35}$ There were a few patients in the control and dorzolamide groups whose IOP levels reached up to $40 \mathrm{mmHg}$ during the first 16 hours and returned to preoperative levels by 48 hours. Conversely, there were two $(3.8 \%)$ patients from the dorzolamide group and only one $(1.9 \%)$ patient in the control group whose IOP was lower than $5 \mathrm{mmHg} 16$ hours postoperatively. Close examination of these cases revealed deep anterior chambers and no wound leak. Significantly, the IOP returned to normal after 48 hours postoperatively and no complications were reported. This finding may represent suboptimal anterior chamber inflation at the conclusion of surgery ${ }^{36}$ or ciliary body shutdown secondary to the peribulbar anesthesia. 
Table 2 Preoperative and postoperative mean IOP $(\mathrm{mmHg})$

\begin{tabular}{|c|c|c|c|c|c|c|c|}
\hline \multirow[t]{2}{*}{ Time } & \multicolumn{7}{|c|}{ Mean IOP change (mmHg) + DS (Range) } \\
\hline & Control group & Range & $\begin{array}{l}\text { Acetazolamide } \\
\text { group }\end{array}$ & Range & $\begin{array}{l}\text { Dorzolamide } \\
\text { group }\end{array}$ & Range & $\begin{array}{l}\text { P Value between groups } \\
\text { and within groups }\end{array}$ \\
\hline Preoperative & $12.09 \pm 3.19$ & 15 & $12.08 \pm 3.67$ & 16 & $10.63 \pm 2.87$ & 11 & 0.035 \\
\hline \multicolumn{8}{|l|}{ Postoperative } \\
\hline 16 hours & $16.80 \pm 8.04$ & 37 & $13.11 \pm 6.08$ & 24 & $17.80 \pm 8.22$ & 36 & 0.008 \\
\hline 24 hours & $11.66 \pm 5.11$ & 26 & $10.61 \pm 4.26$ & 22 & $11.74 \pm 5.03$ & 29 & 0.452 \\
\hline 48 hours & $10.90 \pm 3.65$ & 18 & $10.01 \pm 2.34$ & 13.5 & $9.75 \pm 2.99$ & 18 & 0.138 \\
\hline
\end{tabular}

Abbreviation: IOP, intraocular pressure.

Acetazolamide $250 \mathrm{mg}$ one tablet one hour preoperatively followed by half a tablet $125 \mathrm{mg}$ every eight hours showed a statistically significant reduction in the IOP spike postoperatively at 16,24 , and 48 hours. A previous study reported the preoperative use of topical dorzolamide ${ }^{37}$ and a dorzolamide-timolol combination. ${ }^{38}$ These were effective in reducing IOP at six and 24 hours. Another study using acetazolamide $500 \mathrm{mg}$ administered at one hour before surgery showed significantly reduced IOP at four to six hours and 24 hours and fewer pressure spikes above $35 \mathrm{mmHg} .{ }^{39}$ However, another study using the same dose one hour after surgery found no significant benefit. ${ }^{40}$

Carbonic anhydrase inhibitors have been used to treat glaucoma since 1954, when Becker ${ }^{41}$ first demonstratezthe clinical efficacy of acetazolamide. CAIs are sulfonamide derivatives that lower IOP by decreasing aqueous

Table 3 Mean difference IOP change $(\mathrm{mmHg}) \pm$ SE from preoperative to 16, 24, and 48 hours postoperatively

\begin{tabular}{|c|c|c|c|c|c|}
\hline $\begin{array}{l}\text { Dependent } \\
\text { variable }\end{array}$ & (I) medicine & (J) medicine & $\begin{array}{l}\text { Mean } \\
\text { difference (I-J) }\end{array}$ & $\begin{array}{l}\text { Std } \\
\text { Error }\end{array}$ & Sig \\
\hline \multirow[t]{6}{*}{ Base IOP } & Control groups & Acetazolamide groups & 0.01 & 0.66 & 1 \\
\hline & & Dorzolamide groups & 1.46 & 0.63 & 0.073 \\
\hline & Acetazolamide groups & Control groups & -0.01 & 0.66 & I \\
\hline & & Dorzolamide groups & 1.44 & 0.66 & 0.093 \\
\hline & Dorzolamide groups & Control groups & -1.46 & 0.63 & 0.073 \\
\hline & & Acetazolamide groups & -1.44 & 0.66 & 0.093 \\
\hline \multirow[t]{6}{*}{ IOP 16 hours } & Control groups & Acetazolamide groups & 3.69 & 1.54 & 0.061 \\
\hline & & Dorzolamide groups & -0.98 & 1.48 & 0.803 \\
\hline & Acetazolamide groups & Control groups & -3.69 & 1.54 & 0.061 \\
\hline & & Dorzolamide groups & -4.67 & 1.54 & 0.011 \\
\hline & Dorzolamide groups & Control groups & 0.98 & 1.48 & 0.803 \\
\hline & & Acetazolamide groups & 4.67 & 1.54 & 0.011 \\
\hline \multirow[t]{6}{*}{ IOP 24 hours } & Control groups & Acetazolamide groups & 1.05 & 0.99 & 0.57 \\
\hline & & Dorzolamide groups & -0.08 & 0.96 & I \\
\hline & Acetazolamide groups & Control groups & -1.05 & 0.99 & 0.57 \\
\hline & & Dorzolamide groups & -1.13 & 0.98 & 0.519 \\
\hline & Dorzolamide groups & Control groups & 0.08 & 0.95 & I \\
\hline & & Acetazolamide groups & 1.13 & 0.98 & 0.519 \\
\hline \multirow[t]{6}{*}{ IOP 48 hours } & Control groups & Acetazolamide groups & 0.9 & 0.63 & 0.36 \\
\hline & & Dorzolamide groups & 1.15 & 0.6 & 0.162 \\
\hline & Acetazolamide groups & Control groups & -0.9 & 0.63 & 0.36 \\
\hline & & Dorzolamide groups & 0.25 & 0.62 & 0.92 \\
\hline & Dorzolamide groups & Control groups & -1.15 & 0.6 & 0.162 \\
\hline & & Acetazolamide groups & -0.25 & 0.62 & 0.92 \\
\hline
\end{tabular}

Note: The mean difference is significant at the 0.05 level.

Abbreviations: IOP, intraocular pressure; SE, standard error. 
humor formation. These drugs inhibit carbonic anhydrase, which is one of the enzymes that regulate aqueous humor formation. Systemic administration of CAIs is extremely effective in reducing IOP in most patients but is accompanied by side effects that can range from mild and annoying to debilitating and life threatening, the latter necessitating discontinuation of these drugs. On rare occasions, CAIs may induce irreversible blood dyscrasias, which can be fatal. The substantial incidence of side effects and the rare occurrence of fatal complications have led to controversy regarding the usefulness of and indications for systemically administered CAIs in the chronic management of glaucoma. ${ }^{42} \mathrm{CAIs}$ reduce IOP by inhibiting aqueous humor formation. This has been demonstrated with the use of indirect measurement techniques ${ }^{43,44}$ as well as direct fluorophotometric measurement techniques of aqueous humor flow rates. ${ }^{45-47}$ Fluorophotometric studies have documented reductions in aqueous humor flow rates of $21 \%$ to $40 \%$ in normal human volunteers and in a few glaucoma patients after acute oral dosing with 250 to $750 \mathrm{mg}$ acetazolamide. ${ }^{45-47}$ McCannel and colleagues ${ }^{24}$ found that acetazolamide reduced aqueous flow rates by $24 \%$ below the nocturnal flow rate in the eye of a sleeping patient. Timolol does not produce such reactions.

In conclusion, we found that acetazolamide effectively reduced the IOP spike, 16 hours and 24 to 48 hours after scleral tunnel cataract surgery with hard posterior chamber IOL implantation. The mean IOP significantly increased in placebo and dorzolamide groups, 16 hours after surgery. IOP monitoring in the early postoperative period is still necessary after scleral tunnel cataract surgery with viscoelastic substance. It may be possible therefore to select patients at greater risk who developed ocular hypertension after cataract surgery to receive prophylactic IOP-lowering treatment. This would minimize patient morbidity yielding significant health economic savings.

\section{Acknowledgments}

I would like to thank my coauthors, Dr Motaher Al-Shaer, Dr Nabil Al-Matary, and Dr Mahfoud Bamashmous. Also many thanks are extended to Dr Yahia Raja and Dr Adnan Al-Adhal at the Department of Community Medicine and Department of Pharmacology, respectively, Sana'a University for their co-operation in evaluation of statistical analysis. I would like to thank all ophthalmic surgeons who did the work including the theatre attendants at the ophthalmic department, Sana'a University. Finally I wish to thank Dr Talal A. Haider, head of the ophthalmic department of Sana'a University for his research advice. The authors report no conflicts of interest in this work.

\section{References}

1. The Royal College of Ophthalmologists. Cataract Surgery Guidelines. London: The Royal College of Ophthalmologists; 2001.

2. Cohen VML, Demetria H, Jordan K, et al. First day post-operative review following uncomplicated phacoemulsification. Eye. 1998;12: 634-636.

3. McKellar MJ, Elder MJ. The early complications of cataract surgery; is routine review of patients 1 week after cataract extraction necessary? Ophthalmology. 2001;108:930-935.

4. Ahmed IIK, Kranemann C, Chipman M, Malam F. Revisiting early postoperative follow-up after phacoemulsification. J Cataract Refract Surg. 2002;28:100-108.

5. Allan BDS, Baer RM, Heyworth P, et al. Conventional routine clinical review may not be necessary after uncomplicated phacoemulsification. Br J Ophthalmol. 1997;81:548-550.

6. Whitefield L, Crowston J, Little BC. First day follow up for routine phacoemulsification? Br J Ophthalmol. 1996;80:148-150.

7. Ruiz RS, Wilson CA, Musgrove KH, Prager TC. Management of increased intraocular pressure after cataract extraction. Am J Ophthalmol. 1987;103:487-491; erratum 1987;104:195.

8. Gupta A, Bansal RK, Grewal SPS. Natural course of intraocular pressure after cataract extraction and the effect of intracameral carbachol. J Cataract Refract Surg. 1992;18:166-169.

9. Wedrich A, Menapace R. Intraocular pressure following small-incision cataract surgery and polyHEMA posterior chamber lens implantation; a comparison between acetylcholine and carbachol. J Cataract Refract Surg. 1992;18:500-505.

10. Bo"hmer TG, Lagre'ze WD, Funk J. Intraocular pressure rise after phacoemulsification with posterior chamber lens implantation: effect of prophylactic medication, wound closure, and surgeon's experience. Br J Ophthalmol. 1995;79:809-813.

11. Gross JG, Meyer DR, Robin AL, et al. Increased intraocular pressure in the immediate postoperative period after extracapsular cataract extraction. Am J Ophthalmol. 1988;105:466-469.

12. Glasser DB, Matsuda M, Edelhauser HF. A comparison of the efficacy and toxicity of an intraocular pressure response to viscous solutions in the anterior chamber. Arch Ophthalmol. 1986;104:1819-1824.

13. Fry LL, Yee RW. Healon GV in extracapsular cataractextraction with intraocular lens implantation. J Cataract Refract Surg. 1993;19: 409-412.

14. Kohnen T, von Her M, Schu"tte E, Koch DD. Evaluation of intraocular pressure with Healon and Healon GV in sutureless cataract surgery with foldable lens implantation. J Cataract Refract Surg. 1996;22:227-237

15. Lehmann R, Brint S, Stewart R, et al. Clinical comparison of Provisc and Healon in cataract surgery. J Cataract Refract Surg. 1995;21: $543-547$.

16. Arshinoff SA, Hofman I. Prospective, randomized trial comparing MicroVisc Plus and Healon GV in routine phacoemulsification. J Cataract Refract Surg. 1998;24:814-820.

17. Rainer G, Menapace R, Findl O, Petternel V, Kiss B, Georgopoulos M. Intraindividual comparison of the effects of a fixed dorzolamide-timolol combination and latanoprost on intraocular pressure after small incision cataract surgery. J Cataract Refract Surg. 2001;27(5):706-710.

18. Chakraborty P, Villada JR, Tinu A. Medical control of IOP after cataract surgery. J Cataract Refract Surg. 2000;26(2):162.

19. Naeser K, Thim K, Hansen TE, et al. Intraocular pressure in the first days after implantation of posterior chamber lenses with the use of sodium hyaluronate (Healont). Acta Ophthalmol. 1986;64:330-337.

20. Mastropasqua L, Carpineto P, Ciancaglini M, Falconio G. Intraocular pressure changes after phacoemulsification and foldable silicone lens implantation using Healon GVt. Ophthalmologica. 1998;212: 318-321. 
21. Passo MS, Ernest JT, Goldstick TK. Hyaluronate increases intraocular pressure when used in cataract extraction. Br J Ophthalmol. 1985;69: $572-575$.

22. Byrd S, Singh K. Medical control of intraocular pressure after cataract surgery. J Cataract Refract Surg. 1998;24:1493-1497.

23. Obstbaum SA, Galin MA. The effects of timolol on cataract extraction and intraocular pressure. Am J Ophthalmol. 1979;88:1017-1019.

24. McCannel CA, Heinrich SR, Brubaker RF. Acetazolamide but not timolol lowers aqueous humor flow in sleeping humans. Graefes Arch Clin Exp Ophthalmol. 1992;230:518-520.

25. Haimann MH, Phelps CD. Prophylactic timolol for the prevention of high intraocular pressure after cataract extraction; a randomized, prospective, double-blind trial. Ophthalmology. 1981;88:233-238.

26. Fry LL. Comparison of the postoperative intraocular pressure with Betagan, Betoptic, Timoptic, Iopidine, Diamox, Pilopine Gel, and Miostat. J Cataract Refract Surg. 1992;18:14-19.

27. Hollands RH, Drance SM, House PH, Schulzer M. Control of intraocular pressure after cataract extraction. Can J Ophthalmol. 1990;25: $128-132$.

28. Wedrich A, Menapace A. Effect of acetylcholine on intraocular pressure following small-incision cataract surgery. Ophthalmologica. 1992;205:125-130.

29. Ruiz RS, Rhem MN, Prager TC. Effects of carbachol and acetylcholine on intraocular pressure after cataract extraction. Am J Ophthalmol. 1989;107:7-10.

30. Byrd S, Singh K. Medical control of intraocular pressure after cataract surgery. J Cataract Refract Surg. 1998;24:1493-1497.

31. Obstbaum SA, Galin MA. The effects of timolol on cataract extraction and intraocular pressure. Am J Ophthalmol. 1979;88:1017-1019.

32. Henry JC, Olander K. Comparison of the effect of four viscoelastic agents on early postoperative intraocular pressure. J Cataract Refract Surg. 1996;22:960-966.

33. Jürgens I, Matheu A, Castilla M. Ocular hypertension after cataract surgery: a comparison of three surgical techniques and two viscoelastics. Ophthalmic Surg Lasers. 1997;28:30-36.

34. Gross JG, Meyer DR, Robin AL, et al. Increased intraocular pressure in the immediate postoperative period after extracapsular cataract extraction. Am J Ophthalmol. 1988;105:466-469.
35. Lagrèze W-DA, Bömer TG, Funk J. Effect of surgical technique on the increase in intraocular pressure after cataract extraction. Ophthalmic Surg Lasers. 1996;27:169-173; erratum, 400.

36. Shingleton BJ, Wadhwani RA, O’Donoghue MW, et al. Evaluation of intraocular pressure in the immediate period after phacoemulsification. $J$ Cataract Refract Surg. 2001;27:524-527.

37. Rainer G, Menapace R, Schmetterer K, et al. Effect of dorzolamide and latanoprost on intraocular pressure after small incision cataract surgery. J Cataract Refract Surg. 1999;25:1624-1629.

38. Rainer G, Menapace R, Findl O, et al. Intraindividual comparison of the effects of a fixed dorzolamide-timolol combination and latanoprost on intraocular pressure after small incision cataract surgery. J Cataract Refract Surg. 2001;27:706-710.

39. Byrd S, Singh K. Medical control of intraocular pressure after cataract surgery. J Cataract Refract Surg. 1998;24:1493-1497.

40. Bo“mer TG, Lagre 'zeW-DA, Funk J. Intraocular pressure rise after phacoemulsification with posterior chamber lens implantation: effect of prophylactic medication, wound closure, and surgeon's experience. Br J Ophthalmol. 1995;79:809-813.

41. Becker B. Decrease in intraocular pressure in man by a carbonic anhydrase inhibitor, Diamox: a preliminary report. Am J Ophthalmol. 1954;37:13-15.

42. Tasman W, Jaeger EA, editors. Duane's Ophthalmology. Baltimore, MA: Lippincott Williams \& Wilkins; 2007.

43. Becker B. The mechanism of the fall in intraocular pressure induced by the carbonic anhydrase inhibitor, Diamox. Am J Ophthalmol. 1955;39:177-184

44. Becker B. Carbonic anhydrase and the formation of aqueous humor: The Friedenwald Memorial Lecture. Am J Ophthalmol. 1959;47:342-361.

45. Bloom JN, Levene RZ, Thomas G, et al. Fluorophotometry and the rate of aqueous flow in man: I. Instrumentation and normal values. Arch Ophthalmol. 1976;94:435-443.

46. Dailey RA, Brubaker RF, Bourne WM. The effects of timolol maleate and acetazolamide on the rate of aqueous formation in normal human subjects. Am J Ophthalmol. 1982;93:232-237.

47. Desai P, Minassian DC, Reidy A. National Cataract Surgery Survey 1997-8: a report of the results of the clinical outcomes. Br J Ophthalmol. 1999;83:1336-1340.
Clinical Ophthalmology

\section{Publish your work in this journal}

Clinical Ophthalmology is an international, peer-reviewed journal covering all subspecialties within ophthalmology. Key topics include: Optometry; Visual science; Pharmacology and drug therapy in eye diseases; Basic Sciences; Primary and Secondary eye care; Patient Safety and Quality of Care Improvements. This journal is indexed on

\section{Dovepress}

PubMed Central and CAS, and is the official journal of The Society of Clinical Ophthalmology (SCO). The manuscript management system is completely online and includes a very quick and fair peer-review system, which is all easy to use. Visit http://www.dovepress.com/ testimonials.php to read real quotes from published authors. 